\title{
Development of Discriminating Method for Dissolution of Aceclofenac Marketed Formulations
}

\author{
Tejal Soni ${ }^{1,4}$, Chirag Nagda ${ }^{2}$,Tejal Gandhi ${ }^{2}$, and N. P. Chotai ${ }^{3}$ \\ 'Department of Pharmaceutics, Anand Pharmacy College, Anand, Gujarat, India \\ 2 Department of Pharmaceutics, Indukaka College of Pharmacy, New Vallabh-Vidyanagar, \\ Gujarat, India \\ ${ }^{3}$ Department of Pharmaceutics, A. R. College of Pharmacy, Vallabh-Vidyanagar, Gujarat, India
}

\begin{abstract}
The development of a meaningful dissolution procedure for drug products with limited water solubility has been a challenge to the pharmaceutical industry. Aceclofenac (BCS Class II drug) is a nonsteroidal anti-inflammatory drug. There is no official dissolution medium available in the literature. In the present study, parameters such as solubility, medium pH, surfactant type, dissolution behavior of formulations, influence of sink conditions, stability, and discriminatory effect of dissolution testing were studied for the selection of a proper dissolution medium. Results of solubility data revealed that solubility increased with an increase in $\mathrm{pH}$. Sink conditions were exhibited in all media except double-distilled water and $0.1 \mathrm{~N} \mathrm{HCl}$. The drug and marketed formulations were stable in the dissolution media used. An agitation speed of $50 \mathrm{rpm}$ showed a more discriminating drug release profile than $75 \mathrm{rpm}$. The discriminating dissolution method for aceclofenac formulation is paddle at $50 \mathrm{rpm}, 900 \mathrm{~mL} \mathrm{pH} 6.8$ phosphate buffer, greater than $80 \%$ of the label amount is released over 60 minutes.
\end{abstract}

\section{INTRODUCTION}

Do he development of a meaningful dissolution procedure for drug products with limited water solubility has been a challenge to both the pharmaceutical industry and the agencies that regulate them. Low-solubility drugs are usually lipophilic, and drug release is usually the rate-limiting process for oral drug absorption of these substances (1-3). Both in vivo physiology and the physicochemical characteristics of the drugs are important to the oral absorption of poorly water-soluble drugs. In vivo, the dissolution process depends on physicochemical parameters, which may be affected by the intraluminal conditions in the body. Naturally occurring surfactants solubilize sparingly soluble drugs in the body and help in the absorption process. A dissolution medium containing surfactant can better simulate the environment of the gastrointestinal tract than a medium containing organic solvents or other non-physiological substances, making the dissolution test conditions more useful in evaluating drug quality $(4,5)$. Specific information about the drug substance solubility, drug substance stability as a function of $\mathrm{pH}$, and BCS Classification will direct the expedient selection of a proper dissolution medium. A sensitive, reliable in vitro dissolution procedure is used to determine the quality of a product and to advance the evolution of dissolution technology. A clear trend has emerged where the dissolution test has moved from a traditional quality

${ }^{4}$ Corresponding author. control test to a surrogate in vitro bioequivalence (BE) study $(6,7)$.

Aceclofenac (BCS Class II drug) is a non-steroidal anti-inflammatory drug that acts via multifactor mechanisms and is used to treat pain and inflammation. It is practically insoluble in water. Because there is no official dissolution medium available in the monographs, the objective of this study was to develop a discriminating dissolution method for aceclofenac solid oral dosage forms to support product development and quality control efforts.

\section{EXPERIMENTAL \\ Materials}

Aceclofenac was a gift from Mepro Pharmaceutical Pvt. Ltd., Surendranagar. Sodium lauryl sulfate (SLS), Tween 80, potassium dihydrogen orthophosphate, sodium dihydrogen orthophosphate (Qualigens,Mumbai), sodium hydroxide (S.D.Fine chemicals, Mumbai), methanol (AR grade), and hydrochloric acid (Merck, Darmstadt, Germany) were used. Double-distilled water was used throughout the study.

\section{Methods \\ Saturation Solubility Study}

The saturation solubility of aceclofenac (ACE) was determined in the following: double-distilled water; 0.6 , $0.8,1.0,1.5$, and $2 \%(\mathrm{w} / \mathrm{v})$ SLS in water; $0.1,0.2,0.5,1$, and $2 \%$ Tween in water; $0.1 \mathrm{~N} \mathrm{HCl} ; \mathrm{pH} 4.5$ acetate buffer; and $\mathrm{pH} 6.8$ phosphate buffer at $37^{\circ} \mathrm{C}$. Excess ACE was added to 
$100 \mathrm{~mL}$ of dissolution medium in a conical flask and agitated continuously at room temperature for $8 \mathrm{~h}$ on a shaker. The solutions were kept aside for $6 \mathrm{~h}$ until equilibrium was achieved. The solutions were then filtered through No. 41 Whatman filter paper, and the filtrate was suitably diluted and analyzed spectrophotometrically at 275 nm (UV-vis spectrophotometer, Shimadzu-1750).

\section{In Vitro Drug Release Study}

A batch of 20 tablets of ACE was procured for comparative studies of different brands. The dissolution experiment was performed using USP Apparatus 2 at $37 \pm$ $2{ }^{\circ} \mathrm{C}$ with paddle speeds of $50 \pm 5 \mathrm{rpm}$ and $75 \pm 5 \mathrm{rpm}$ in $900 \mathrm{~mL}$ dissolution medium (Electrolab, TOD-08L). A 5-mL sample was withdrawn at different time intervals and filtered through No. 41 Whatman filter paper.The same volume of fresh medium was replaced to maintain constant volume. The sample was suitably diluted and analyzed using a UV-vis spectrophotometer at $275 \mathrm{~nm}$.

\section{Stability Study}

Solutions of pure ACE and drug formulation A (after dissolution) in different media were stored in the dark at ambient temperature and at $2-8{ }^{\circ} \mathrm{C}$ for up to seven days. Sample aliquots of $5 \mathrm{~mL}$ were withdrawn, suitably diluted and analyzed spectrophotometrically after every $24-h$ period. Each day the concentrations of drug found in the standard and formulation were compared with concentrations of drug found in the same samples stored at $2-8{ }^{\circ} \mathrm{C}$. The absolute differences between the results at time zero and the time indicated for stability were determined by analyzing the content using a UV-vis spectrophotometer.

\section{Comparison of Dissolution Profiles by a Model-Independent Method}

This study utilized a model-independent approach in which the dissolution profiles of two drug products are compared using the fit factor. This fit factor directly compares the difference between percent drug dissolved per unit time for a test and a reference product. The fit factor, $f_{2}$, is defined by the following:

$$
f_{2}=50 \log \left\{\left[1+\left(\frac{1}{n}\right) \sum_{t=1}^{n}\left(R_{t}-T_{t}\right)^{2}\right]^{-0.5} \times 100\right\}
$$

where $n$ is the number of dissolution sampling times, and $R_{t}$ and $T_{t}$ are the individual or mean percent dissolved at each time point for the reference and test dissolution profiles, respectively (17).

\section{RESULTS}

The results of the solubility study and the influence of sink conditions are summarized in Table 1 and show that there was a significant increase in solubility with increasing $\mathrm{pH}$. The solubility of ACE in double-distilled
Table 1. Saturation Solubility of Aceclofenac and Relative Sink Conditions in Different Dissolution Media ( $\mathrm{n}=3)_{\text {.** }}$

\begin{tabular}{lcc}
\hline Dissolution Medium & $\begin{array}{c}\text { Solubility } \\
\text { (mean } \pm \text { SD) } \mu \mathrm{g} / \mathrm{mL}\end{array}$ & $\begin{array}{c}\text { Sink Condition } \\
\mathrm{C}_{\mathrm{s}} / \mathrm{C}_{\mathrm{d}}\end{array}$ \\
\hline Double-distilled water & $58.67 \pm 0.101$ & 0.52803 \\
\hline $0.6 \%$ w/v SLS in D.D. water & $453.2 \pm 1.295$ & 4.0788 \\
\hline $0.8 \%$ w/v SLS in D.D. water & $466.6 \pm 2.185$ & 4.1994 \\
\hline $1 \%$ w/v SLS in D.D. water & $731.7 \pm 0.952$ & 6.583 \\
\hline $1.5 \%$ w/v SLS in D.D. water & $724.69 \pm 0.877$ & 6.522 \\
\hline $2 \%$ w/v SLS in D.D. water & $813.36 \pm 1.144$ & 7.3202 \\
\hline $0.2 \%$ v/v Tween 80 in D.D. water & $855.17 \pm 2.44$ & 7.6965 \\
\hline $0.5 \%$ v/v Tween 80 in D.D.water & $1019.8 \pm 1.187$ & 9.178 \\
\hline $1 \%$ v/v Tween 80 in D.D. water & $798.8 \pm 1.153$ & 7.1892 \\
\hline $2 \%$ v/v Tween 80 in D.D. water & $782.0 \pm 1.89$ & 7.038 \\
\hline $0.1 \mathrm{~N}$ HCl (pH 1.2) & $21.93 \pm 0.257$ & 0.1973 \\
\hline Acetate buffer pH 4.5 & $995.0 \pm 0.810$ & 8.955 \\
\hline Phosphate buffer pH 6.8 & $1538.7 \pm 1.215$ & 13.84 \\
\hline
\end{tabular}

${ }^{*} C_{s}$ indicates saturation solubility of aceclofenac in $900 \mathrm{~mL}$ dissolution medium; $C_{d}$ dose of aceclofenac in tablet formulation; D.D indicates double-distilled; and SLS is sodium lauryl sulfate.

water was found to be $58.67 \mu \mathrm{g} / \mathrm{mL}$. The addition of different concentrations of SLS significantly increased solubility by up to 13.4 -fold. Solubility decreased with Tween 80 at concentrations of $1 \%$ and higher. The maximum solubility was $1538 \mu \mathrm{g} / \mathrm{mL}$ in $\mathrm{pH} 6.8$ phosphate buffer (Figure 1). In the present study, the value of $C_{s} / C_{d}$ was $<3$ in water and in $0.1 \mathrm{~N} \mathrm{HCl}$ medium (i.e., the ratio of saturation solubility to the dose in $900 \mathrm{~mL}$ dissolution medium exhibited non-sink conditions). This was improved by the addition of surfactant to the medium.

The mean cumulative percentage of drug dissolved in $2 \%$ SLS was $73 \%$ in 60 min, while in the case of nonionic surfactant, the dissolution rate decreased with the

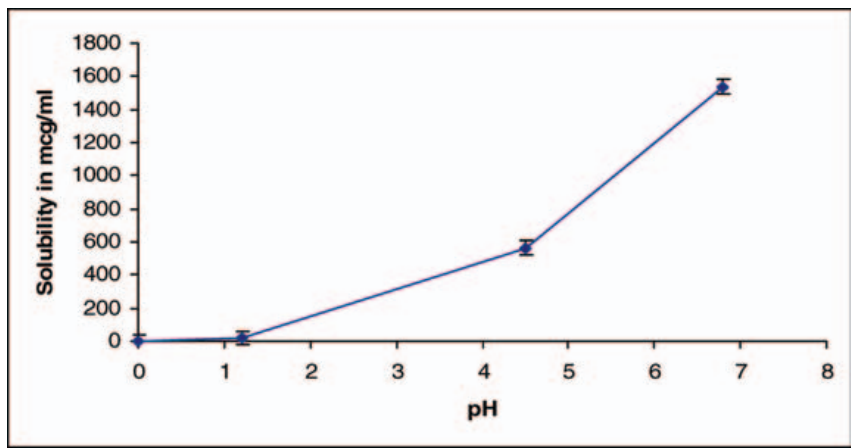

Figure 1.pH-solubility profile of aceclofenac. Each point refers to mean $\pm S D$ $(n=3)$ 
addition of surfactant at concentrations of $1 \%$ and higher (Figure2). Greater than $80 \%$ drug release was found within 60 min in $\mathrm{pH} 6.8$ phosphate buffer medium.

Table 2 contains a summary of the stability data for standards and samples. The absolute difference between the concentrations of drug stored at $2-8^{\circ} \mathrm{C}$ and the same solution at room temperature over the period of 7 days was found to be less than $3.0 \%$ for all media. Correlation of the solubility data, stability data, and influence of sink conditions showed $\mathrm{pH} 6.8$ phosphate buffer to be a suitable medium.

The percentage cumulative drug release (\% CDR) for marketed formulations $\mathrm{A}, \mathrm{B}$, and $\mathrm{C}$ in $\mathrm{pH} 6.8$ phosphate buffer was compared at $50 \pm 5 \mathrm{rpm}$ and $75 \pm 5 \mathrm{rpm}$

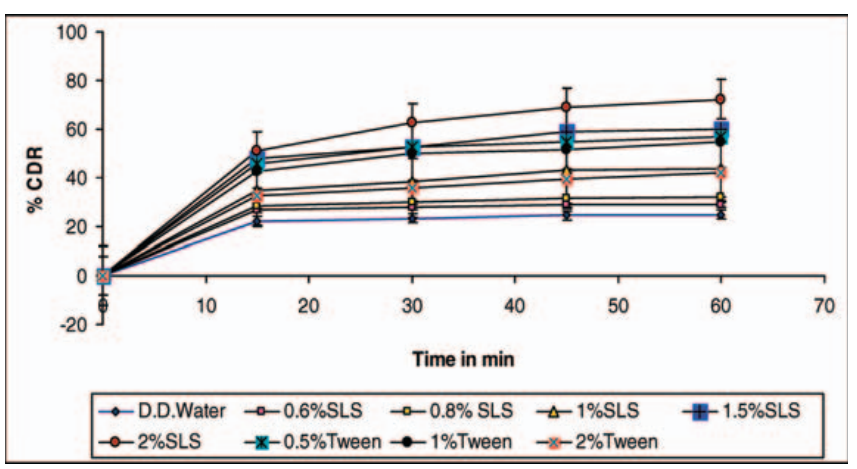

Figure 2. Dissolution profile of formulation $A$ in various aqueous media containing surfactant. Each point refers to mean $\pm S D(n=3) ; \% C D R$ represents percentage of cumulative drug release.

Table 2. Stability Study Data (percentage of absolute difference) of Aceclofenac Standard Solutions and Aceclofenac Formulation A in Various Dissolution Media on Day 7.

\begin{tabular}{llc}
\hline Medium & Standard (\%) & Sample (\%) \\
\hline Double-distilled water & 2.26 & 2.45 \\
\hline $0.6 \%$ w/v SLS in D.D. water & 1.85 & 1.50 \\
\hline $0.8 \%$ w/v SLS in D.D. water & 1.56 & 1.89 \\
\hline $1 \%$ w/v SLS in D.D. water & 0.895 & 0.888 \\
\hline $1.5 \%$ w/v SLS in D.D. water & 0.503 & 0.626 \\
\hline $2 \%$ w/v SLS in D.D.water & 0.58 & 0.989 \\
\hline $0.5 \%$ v/v Tween 80 in D.D. water & 1.69 & 1.99 \\
\hline $1 \%$ v/v Tween 80 in D.D. water & 1.78 & 1.94 \\
\hline $2 \%$ v/v Tween 80 in D.D. water & 2.07 & 2.61 \\
\hline $0.1 \mathrm{~N}$ HCl (pH 1.2) & 1.229 & 1.342 \\
\hline Acetate buffer pH 4.5 & 2.07 & 2.48 \\
\hline Phosphate buffer pH 6.8 & 1.05 & 0.855 \\
\hline
\end{tabular}

(Figures 3 and 4). Table 3 contains the statistical evaluation of the cumulative drug release percentage at 50 and 75 rpm for film-coated tablets $A, B$, and $C$ using the Student's $t$-test at the $5 \%$ significance level. The $P$ value less than or equal to the delineated significance level (0.05) indicates that there is a statistically significant difference in the drug release in formulations at varying speeds of rotation. A significant difference in \% CDR was found for formulations $A$ and $C$ with varying speed, while no statistically significant difference was found for formulation B (ACE with $\beta$-cyclodextrin).

Table 4 shows a comparison of the dissolution profiles of marketed products using the similarity factor $f_{2}$ at different stirring speeds in $\mathrm{pH} 6.8$ phosphate buffer. Similarity was found in formulations $B$ and $C$ with reference product $A$ at $75 \pm 5 \mathrm{rpm}$, while dissimilarity was found in formulation $B$ with reference product $A$ at $50 \pm 5 \mathrm{rpm}$.

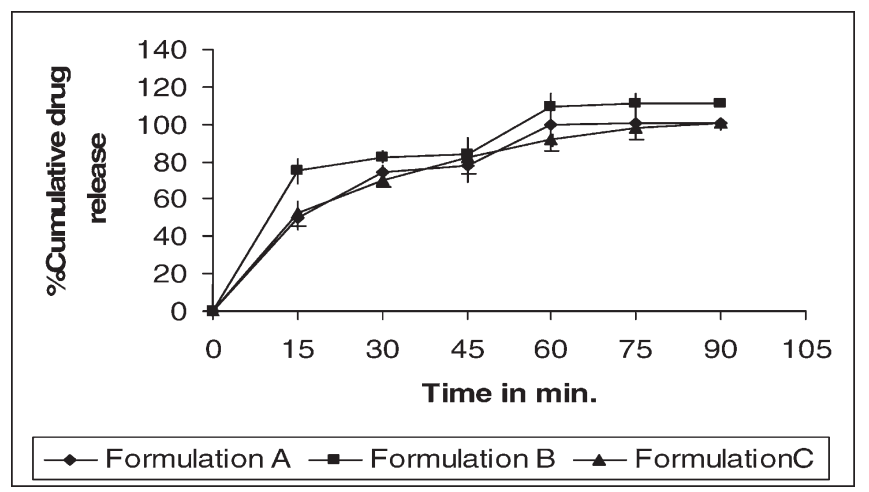

Figure 3. Dissolution profile of three marketed aceclofenac tablet formulations in $\mathrm{pH} 6.8$ phosphate buffer at $50 \mathrm{rpm}$. Each point refers to mean $\pm S D(n=6)$.

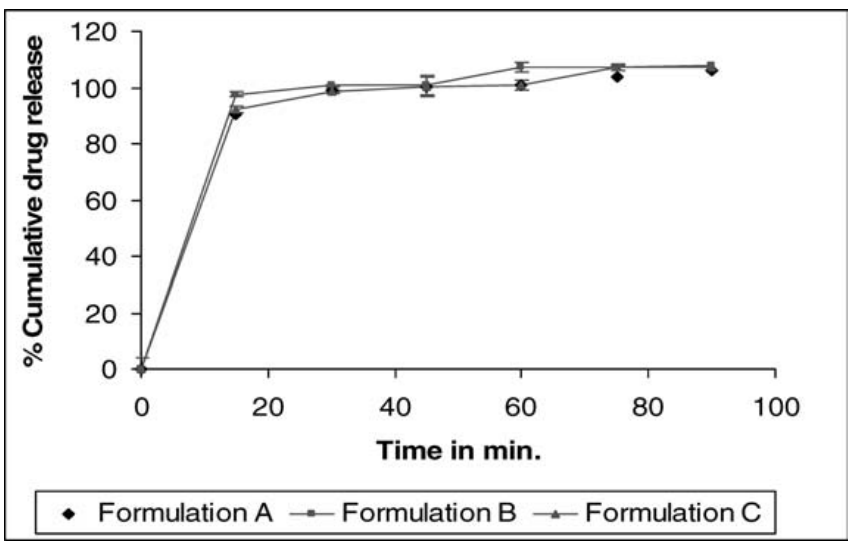

Figure 4. Dissolution profile of three marketed aceclofenac tablet formulations in $\mathrm{pH} 6.8$ phosphate buffer at $75 \mathrm{rpm}$. Each point refers to mean $\pm S D(n=6)$. 
Table 3. Statistical Evaluation of Dissolution Results for Formulation A, B, and C Film-Coated Tablets at Different Stirring Speeds in pH 6.8 Phosphate Buffer Medium.

\begin{tabular}{|c|c|c|c|c|c|}
\hline \multirow[b]{2}{*}{ Formulation } & \multirow[b]{2}{*}{ Time } & \multicolumn{2}{|c|}{$\begin{array}{l}\text { \% Cumulative Drug } \\
\text { Release (CDR) }\end{array}$} & \multirow[b]{2}{*}{$t$-test } & \multirow[b]{2}{*}{$P$ value } \\
\hline & & 50 rpm & $75 \mathrm{rpm}$ & & \\
\hline A & $\begin{array}{r}0 \\
15 \\
30 \\
45 \\
60 \\
75 \\
90\end{array}$ & $\begin{array}{c}0 \\
49.95 \\
74.496 \\
77.622 \\
100.024 \\
100.49 \\
100.5\end{array}$ & $\begin{array}{c}0 \\
90.29 \\
99.34 \\
100.2 \\
100.98 \\
103.9 \\
105.89\end{array}$ & 2.38 & 0.05 \\
\hline B & $\begin{array}{r}0 \\
15 \\
30 \\
45 \\
60 \\
75 \\
90\end{array}$ & $\begin{array}{c}0 \\
75.039 \\
82.47 \\
83.8 \\
109.3 \\
110.7 \\
110.7\end{array}$ & $\begin{array}{c}0 \\
97.67 \\
100.7 \\
100.89 \\
107.03 \\
107.06 \\
108.01\end{array}$ & 1.60 & 0.16 \\
\hline$C$ & $\begin{array}{r}0 \\
15 \\
30 \\
45 \\
60 \\
75 \\
90\end{array}$ & $\begin{array}{c}0 \\
52.218 \\
69.835 \\
81.908 \\
92.157 \\
98.2 \\
100.23\end{array}$ & $\begin{array}{c}0 \\
92.09 \\
98.56 \\
100.13 \\
100.86 \\
106.97 \\
107.02\end{array}$ & 3.40 & 0.01 \\
\hline
\end{tabular}

Table 4. Comparison of Film-Coated Tablet Dissolution Profiles through the Similarity Factor $\left(\mathrm{f}_{2}\right)$ at Different Stirring Speeds in pH 6.8 Phosphate Buffer.

\begin{tabular}{lcc}
\hline Stirring Speed (rpm) & Formulation B & Formulation C \\
\hline 50 & 44.11 & 67.62 \\
\hline 75 & 68.075 & 73.266 \\
\hline
\end{tabular}

Formulation $\mathrm{A}$ is reference product.

\section{DISCUSSION}

A dissolution study of dosage forms necessitates modifications in the dissolution medium to increase the solubility. ACE is a lipophilic compound and is practically insoluble in water. ACE is a weak acid, and it is expected that solubility increases with $\mathrm{pH}$. However, the addition of surfactant is a reasonable approach, which if implemented correctly, can approximate the Gl fluid condition. Saturation solubility of ACE in different media increased with an increase in buffer $\mathrm{pH}$ as well as with an increase in surfactant concentration. This significant increase is attributed to the micellar solubilization by SLS.

The ratio of solubility to drug concentration (dose), expressed as $C_{s} / C_{d}$, represents the closeness to sink conditions; a sink condition occurs when the amount of drug that can be dissolved in the dissolution medium is three times greater than the amount of drug to be dissolved. A low $C_{s} / C_{d}$ ratio shows the existence of non-sink conditions. The rate of drug dissolution will be slowed by the limited solubility of the drug in that medium.

In the case of a higher percentage of Tween 80 as compared with SLS, drug dissolution rate was reduced. The reason for this may be that drug dissolution is the result of drug liberation and drug diffusion into the dissolution medium. In this respect, the diffusivity of dissolved species (drug molecule and drug-micelle complex) plays an important role. The diffusivity of drug-micelle complex is several-fold less than for drug alone, and the net change in the dissolution rate is the sum of solubility enhancement and a decline in effective diffusivity. The higher molecular weight of Tween 80 (1310 versus $288.4 \mathrm{~g} / \mathrm{mol})$ and the greater aggregation weight of its micelles $(76,000$ versus $15,900 \mathrm{~g} / \mathrm{mol}$ ) compared with SLS result in lower diffusivity of drug-micelle complex and hence a reduction in the dissolution rate (8-9).

A dissolution medium need not be chosen if the standard solutions are not stable for at least $24 \mathrm{~h}$ at ambient temperature (10). In the present study, the drug was found to be stable in various media alone and in the presence of excipients.

The discriminating power of the method was evaluated by testing three marketed formulations (A, B, and C) having different compositions, of which formulation $B$ contained ACE with $\beta$-cyclodextrin. The most common way to challenge the discriminatory power of the method is to test formulations with differences resulting from changes in the characteristics of the API, drug product composition, product manufacturing process, and stability conditions (11-16). In general, mild agitation conditions should be maintained during dissolution testing to allow maximum discriminatory power (4). In most cases, the dissolution apparatus tends to become less discriminating when operated at faster speeds that result in a flatter drug release profile. For the present study, it can be concluded that the drug release profile at $50 \pm 5 \mathrm{rpm}$ detected small changes in a drug product composition. At $75 \pm 5 \mathrm{rpm}$, dissolution proceeded too quickly and produced a profile that leveled off too early to show discrimination between the formulations. The satisfactory discriminatory power was observed in dissolution at $50 \mathrm{rpm}$.

The FDA guidances on dissolution testing of immediate-release solid oral dosage formulations (15) and bioavailability and bioequivalence studies for oral dosage forms (16) recommend the use of a model-independent mathematical approach proposed by Moore and Flanner (17-22) for calculating similarity factor . An $f_{2}$ value between 50 and 100 represents similarity. In the present study, at the speed of $75 \mathrm{rpm}$, similarity was found in formulations B and C, while at 50 rpm, similarity was not found in formulation B. It can be concluded that the drug release profile at $50 \mathrm{rpm}$ detected small changes in drug product composition. The satisfactory discriminatory power was observed in dissolution at $50 \mathrm{rpm}$. 


\section{CONCLUSION}

Dissolution testing is a very important in vitro test for evaluating drug products. Because there is no dissolution method specified for aceclofenac in the literature, an attempt was made to develop a dissolution method that is discriminating. The use of $900 \mathrm{~mL}$ of $\mathrm{pH} 6.8$ phosphate buffer at $37 \pm 2{ }^{\circ} \mathrm{C}$, a paddle speed of $50 \pm 5 \mathrm{rpm}$ for film-coated formulations, and a 60 -min test provided satisfactory results for all products.

\section{ACKNOWLEDGMENT}

The authors are thankful to Mepro Pharmaceutical Pvt. Ltd, Surendranagar, for providing aceclofenac as a gift sample.

\section{References}

1. Dressman, J. B.; Amidon, G. L.; Reppas, C.; Shah, V.P. Dissolution testing as a prognostic tool for oral drug absorption: immediate release dosage forms. Pharm. Res. 1998, 15, 11-22.

2. Pillay, V.; Fassihi, R. Evaluation and comparison of dissolution data derived from different modified release dosage forms: an alternative method. J. Controlled Release 1998, 55, 45-55.

3. SUPAC-MR: Modified Release Solid Oral Dosage Forms. Scale-Up and Post Approval Changes: Chemistry, Manufacturing, and Controls; In Vitro Dissolution Testing and In Vivo Bioequivalence Documentation; Guidance for Industry; U.S. Department of Health and Human Services, Food and Drug Administration, U.S. Government Printing Office:Washington, DC, 1997.

4. Shah, V. P.; Konecny, J. J.; Everett, R. L.; Mc Cullough, B.; Noorizadeh, A.C.; Skelly, J. P. In vitro dissolution profile of water-insoluble drug dosage forms in the presence of surfactants. Pharm. Res. 1989, 6 (7), 612-618.

5. Carstensen, J.T. Physico-chemical aspects of drug release. In Formulation and Preparation of Dosage Forms, Proceedings of the 37th International Congress of Pharmaceutical Sciences of F.I.P., The Hague, Netherlands, Sept 5-9, 1977; Polderman, J., Ed.; Elsevier: Amsterdam; 1977.

6. Amidon, G. L.; Lennernas, H.; Shah, V. P.; Crison, J. R. A theoretical basis for a biopharmaceutic drug classification: the correlation of in vitro drug product dissolution and in vivo bioavailability. Pharm. Res. 1995, 12, 413-420.

7. Jinno, J.; Oh, D.; Crison, J. R.; Amidon, G. L. Dissolution of ionizable water-insoluble drugs: the combined effect of pH and surfactant. J. Pharm. Sci. 2000, 89 (2), 268-274.

8. Jamzad, S.; Fassihi, R. Role of Surfactant and pH on Dissolution Properties of Fenofibrate and GlipizideA Technical Note. AAPS PharmSciTech 2006, 7 (2),
Article 33. http://www.aapspharmscitech.org/view. asp?art=pt070233 (accessed April 7, 2008).

9. Balakrishnan, A.; Rege, B. D.; Amidon, G. L.; Polli, J. E. Surfactant-mediated dissolution: contributions of solubility enhancement and relatively low micelle diffusivity. J. Pharm. Sci. 2004, 93, 2064-2075.

10. Fortunato, D. Dissolution Method Development for Immediate Release Solid Oral Dosage Forms. Dissolution Technol. 2005, 12 (3), 12-15.

11. Brown, C.; Chokshi, H.; Nickerson, B.; Reed, R.; Rohrs, B.; Shah, P. Acceptable analytical practices for dissolution testing of poorly soluble compounds. Pharm. Technol. 2004, 28 (12), 56-65.

12. Noory, C.; Tran, N.; Ouderkirk, L.; Shah, V.Steps for Development of a Dissolution Test for Sparingly Water-Soluble Drug Products. Dissolution Technol. 2000, 7 (1), 16-18.

13. Siewert, M. FIP Guidelines for Dissolution Testing of Solid Oral Products. Pharm. Ind. 1995, 57, 362-369.

14. Shah, V. P. In Vitro Dissolution Profile of Water Insoluble Drug Dosage Forms in the Presence of Surfactants. Pharm. Res. 1989, 6, 612-618.

15. Dissolution Testing of Immediate Release Solid Oral Dosage Forms; Guidance for Industry; U.S. Department of Health and Human Services, Food and Drug Administration, U.S. Government Printing Office: Washington, DC, 1997.

16. International Pharmaceutical Federation (FIP) guidelines for dissolution testing of solid oral products. Drug Inf. J. 1996, 30, 1071-1084.

17. Moore, J.W.; Flanner, H. H. Mathematical comparison of dissolution profiles. Pharm. Technol. 1996, 20, 64-74.

18. Podczeck, F. Comparison of in vitro dissolution profiles by calculating mean dissolution time (MDT) or mean residence time (MRT). Int. J. Pharm. 1993, 97, 93-100.

19. Polli, J. E.; Rekhi, G. S.; Augsburger, L. L.; Shah, V.P. Methods to compare dissolution profiles and a rationale for wide dissolution specifications for metoprolol tartrate tablets. J. Pharm. Sci. 1997, 86, 690-700.

20. Shah, V. P.; Tsong, Y.; Sathe, P.; Williams, R. L. In Vitro Dissolution Profile Comparison-Statistics and Analysis of the Similarity Factor, $f_{2}$. Pharm. Res. 1998, 15, 889-895.

21. Galia, E.; Nicolaides, E.; Horter, D.; Lobenberg, R.; Reppas, C.; Dressman, J. B. Evaluation of various dissolution media for predicting in vivo performance of class I and II drugs. Pharm. Res. 1998, 15, 698-705.

22. Stella, V. J.; Martodihardjo, S.; Terada, K.; Venkatramana, M. R. Some relationships between the physical properties of various 3-acyloxymethyl prodrugs of phenytoin to structure: potential in vivo performance implication. J.Pharm. Sci. 1998, 87, 1235-1241. 